\title{
How Gold Deposition Affects Anatase Performance in the Photo-catalytic Oxidation of Cyclohexane
}

\author{
Joana T. Carneiro $\cdot$ Chieh-Chao Yang · \\ John A. Moma · Jacob A. Moulijn • \\ Guido Mul
}

Received: 5 September 2008/Accepted: 25 November 2008/Published online: 9 January 2009

(C) The Author(s) 2009. This article is published with open access at Springerlink.com

\begin{abstract}
Gold deposition on Hombikat UV100 was found to negatively affect the activity of this Anatase catalyst in selective photo-oxidation of cyclohexane. By ammonia TPD and DRIFT spectroscopy it was determined that the Au deposition procedure leads to a significant decrease in $\mathrm{OH}$-group density ( $\mathrm{mol} \mathrm{m} \mathrm{m}_{\text {BET }}$ ) on Hombikat, suggesting that the amount of surface OH-groups, rather than the presence or absence of $\mathrm{Au}$, is determining the catalytic performance. The importance of surface $\mathrm{OH}$-groups was demonstrated by comparing the performance of Hombikat (with and without Au deposition) to surface propoxylated $\mathrm{TiO}_{2}$, synthesized by a sol-gel method from titanium (IV) isopropoxide. The effect of the deposition recipe of noble metals on the surface composition of $\mathrm{TiO}_{2}$ should thus be taken into account in evaluating and explaining photocatalytic performance of $\mathrm{TiO}_{2}$ modified by noble metals $(\mathrm{Au})$, in particular in non-aqueous phase reactions.
\end{abstract}

Keywords $\mathrm{TiO}_{2} \cdot$ Titanium (IV) isopropoxide . $\mathrm{Au} \cdot \mathrm{OH}$-group density $\cdot$ Cyclohexane $\cdot$ Oxidation . Photocatalysis · Sol-gel $\cdot$ DRIFT $\cdot \mathrm{NH}_{3}$

J. T. Carneiro · C.-C. Yang · J. A. Moulijn · G. Mul (ه) Catalysis Engineering, DelftChemTech, Delft University of Technology, Julianalaan 136, 2628 BL Delft, The Netherlands e-mail: G.mul@tudelft.nl

J. A. Moma

Project Au-TEK Catalysis, Advanced Materials Division, MINTEK, Private Bag X3015, Randburg, South Africa

\section{Introduction}

Liquid phase oxidation of cyclohexane is an important reaction for the conversion of cyclohexane via cyclohexanone in caprolactam, which is the monomer for nylon- 6 production. The current commercial process is very energetically intensive, and several studies have focused on the direct use of photon energy to selectively oxidize cyclohexane at room temperature using a photocatalyst [1-11]. Although a high ketone over alcohol selectivity is obtained in photocatalytic cyclohexane oxidation, a low conversion (quantum efficiency) and rapid catalyst deactivation prevent application in practice. In order to overcome these problems several improvements can be made in catalyst, reactor [12], and process design [13]. Of the many options to enhance the efficiency of $\mathrm{TiO}_{2}$ photocatalyst, noble metal deposition (Pt, Pd) has been shown to be effective in many occasions. Various studies show that metal deposition enhances the photocatalytic activity of $\mathrm{TiO}_{2}$ in photo degradation reactions in the aqueous phase [14-16], as well as in gas phase applications [17, 18]. Besides modification by $\mathrm{Pt}$ or $\mathrm{Pd}$, modification of Titania by Au has recently been reported to enhance performance in photocatalytic applications involving waste water treatment [19-22]. Most of these studies attribute the enhancement in activity to a decreasing charge carrier recombination velocity [19-21, 23, 24]: a result of localization of electrons on the metal particles.

To the best of our knowledge, the effect of $\mathrm{Au}$ on the performance of $\mathrm{TiO}_{2}$ in the selective photocatalytic oxidation of cyclohexane has not been previously investigated. We will demonstrate that the Au deposition procedure causes dramatic changes in $\mathrm{TiO}_{2}$ surface composition (OH-group population), which we evaluate to be dominant in controlling photocatalyst performance in cyclohexane oxidation, rather than the presence or absence of $\mathrm{Au}$. 


\section{Experimental}

\subsection{Catalyst Preparation}

Hombikat UV100 $\mathrm{TiO}_{2}$ (Sachtleben $\mathrm{GmbH}$ ), was used as received. Hombikat is $100 \%$ anatase as determined by XRD, and has a surface area of $337 \mathrm{~m}^{2} \mathrm{~g}^{-1}$ with a primary particle size of $5 \mathrm{~nm}$ (determined by Scherrer's equation), and a mean agglomerate size in cyclohexane after ultrasonification of $\pm 3 \mu \mathrm{m}$ [4]. Hombikat was used to prepare a $\mathrm{Au}-\mathrm{TiO}_{2}$ photo-catalyst by the deposition precipitation method described by $\mathrm{Yu}$ et al. [25], aiming at a Au loading of $1 \mathrm{wt} \%$. An excess amount of $\mathrm{HAuCl}_{4}$ was dissolved in $230 \mathrm{~mL}$ of deionised water, yielding a concentration of $1.46 \times 10^{-3} \mathrm{M}\left(\mathrm{HAuCl}_{4} 3 \mathrm{H}_{2} \mathrm{O}\right.$, Merck). The $\mathrm{pH}$ of the gold solution was adjusted to 6 with a $0.1 \mathrm{M} \mathrm{NaOH}$ aqueous solution. Then $2 \mathrm{~g}$ Hombikat was added and the suspension stirred for $1 \mathrm{~h}$, at $80{ }^{\circ} \mathrm{C}$. This was followed by filtration and washing with $500 \mathrm{~mL}$ of deionised water. The obtained catalyst was dried at $120{ }^{\circ} \mathrm{C}$, and used without calcination. Throughout the paper Hombikat will be identified by $\mathrm{H}$, and after Au deposition with $\mathrm{Au}-\mathrm{H}$. With the objective to test the effect of the preparation conditions on the performance of Hombikat, a reference material (HT $\mathrm{HCl}$ ) was prepared using $\mathrm{HCl}$ in comparable $\mathrm{Cl}$-amounts to the $\mathrm{HAuCl}_{4}$ solution. Again the $\mathrm{pH}$ of the solution was adjusted to 6 with a $0.1 \mathrm{M} \mathrm{NaOH}$ aqueous solution, followed by Hombikat addition, treatment at $80^{\circ} \mathrm{C}$ for $1 \mathrm{~h}$, filtration, washing and drying at $120^{\circ} \mathrm{C}$.

To further evaluate the effect of Au modification and the importance of surface $\mathrm{OH}$-groups in $\mathrm{TiO}_{2}$ catalyzed photooxidation of cyclohexane, propoxylated $\mathrm{TiO}_{2}$ was synthesized by a sol-gel method. In the preparation procedure, $20 \mathrm{~mL}$ of Titanium (IV) isopropoxide was placed in a beaker and $160 \mathrm{~mL}$ of propan-2-ol added. The solution was placed in an ice bath and vigorously stirred. De-ionized water (pre-adjusted to $\mathrm{pH} 3$ using dilute nitric acid) was added to the solution dropwise until complete precipitation occurred. The gel formed was treated in a water bath at $353 \mathrm{~K}$ for $2 \mathrm{~h}$ under reflux, allowed to cool, filtered, and dried at $393 \mathrm{~K}$ overnight. The material was then ground, screened to less than $107 \mu \mathrm{m}$ diameter and calcined in air at $673 \mathrm{~K}$ for $4 \mathrm{~h}$ applying a heating rate of $2 \mathrm{~K} \mathrm{~min}^{-1}$ [26]. A solution of $4 \mathrm{~mL} \mathrm{HAuCl}_{4}$ (Au concentration of $50 \mathrm{~g} / \mathrm{L}$ ) in $130 \mathrm{~mL}$ of high purity water was heated to $343 \mathrm{~K}$ and its $\mathrm{pH}$ adjusted to 7.5 using a $2 \mathrm{M} \mathrm{Na}_{2} \mathrm{CO}_{3}$ solution. $10 \mathrm{~g}$ of support was then added to the solution and aged for $60 \mathrm{~min}$ with continuous stirring at $400 \mathrm{rpm}$. During the ageing period the temperature of the slurry was maintained at $343 \mathrm{~K}$ and the $\mathrm{pH}$ at 7.5 , using $2 \mathrm{M} \mathrm{Na}_{2} \mathrm{CO}_{3}$ or $0.5 \mathrm{M}$ $\mathrm{HNO}_{3}$. At the end of the ageing time, the slurry was filtered and washed five times; each by re-slurrying in $335 \mathrm{~mL}$ of high purity water for $5 \mathrm{~min}$ followed by filtration. The resulting material was dried at $393 \mathrm{~K}$ overnight, ground and screened to less than $107 \mu \mathrm{m}$ diameter. These two catalysts are referred to as SG (the bare propoxylated $\mathrm{TiO}_{2}$ ), and AuSG after Au deposition. Please note that the $\mathrm{Au}$ deposition $\mathrm{pH}$ used for the $\mathrm{Au}-\mathrm{SG}$ and $\mathrm{Au}-\mathrm{H}$ catalysts was in the $\mathrm{pH}$ range of $6-8$, where $\mathrm{Au}$ morphology is expected to be similar [27].

\subsection{Catalyst Characterization}

Powder X-Ray diffraction (XRD) analysis was performed on a Phillips PW 1840 diffractometer equipped with a graphite monochromator using $\mathrm{Cu}-\mathrm{Ka}$ radiation $(\lambda=$ $0.1541 \mathrm{~nm}$ ). The Scherrer equation was used to calculate the crystal particle size of the samples.

XRF analyses were performed with a Philips PW2400 $\mathrm{X}$-ray fluorescence spectrometer (XRF). The data evaluation was performed with the program Uniquant 5.49.

UV/Vis spectra were recorded on a Perkin-Elmer Lambda 900 spectrometer equipped with an integrating sphere (Labsphere) on porous films of the catalysts, deposited by solvent (water) evaporation under vacuum, onto a $1 \mathrm{~mm}$ thick quartz plate.

Temperature-programmed desorption of ammonia $\left(\mathrm{NH}_{3}-\mathrm{TPD}\right)$ was carried out on a Micromeritics TPR/TPD 2900 apparatus equipped with a thermal conductivity detector (TCD). Approximately $25 \mathrm{mg}$ of each sample was pretreated at $398 \mathrm{~K}$ and rapidly cooled to $373 \mathrm{~K}$ followed by loading with ammonia applying a flow of $30 \mathrm{~mL} \mathrm{~min}^{-1}$ for about $1 \mathrm{~h}$. A He flow of $30 \mathrm{~mL} \mathrm{~min}{ }^{-1}$ was applied to remove weakly adsorbed $\mathrm{NH}_{3}$. A linear temperature program was started $\left(373-873 \mathrm{~K}\right.$ at $\left.10 \mathrm{~K} \mathrm{~min}^{-1}\right)$, and the desorbed amount of ammonia was analyzed by the TCD. The TPD spectra were used to analyze the amount of acidic hydroxyl groups present in the catalyst samples.

Nitrogen adsorption and desorption isotherms were recorded on a QuantaChrome Autosorb-6B at $77 \mathrm{~K}$. Samples were previously evacuated at $623 \mathrm{~K}$ for $16 \mathrm{~h}$ (at a ramp rate of $10 \mathrm{~K} \mathrm{~min}^{-1}$ ). The $\mathrm{BJH}$ model was used to calculate the inter-particle pore size distribution from the adsorption branch, and the BET method was used to calculate the surface area $\left(S_{\mathrm{BET}}\right)$.

Transmission electron microscopy (TEM) was performed using a Philips CM30UT electron microscope with a FEG (field emission gun) as the source of electrons operated at $300 \mathrm{kV}$. Samples were mounted on a Quantifoil microgrid carbon polymer supported on a copper grid.

IR absorption spectra of the solid samples were recorded using a Bruker IFS66 spectrometer with a DTGS detector and equipped with a Spectratech Diffuse Reflectance Accessory, including a high temperature cell. Water was removed from the catalyst surface to facilitate the characterization of the $\mathrm{OH}$-group composition by recording the 
spectra at $120^{\circ} \mathrm{C}$ after equilibration for $1 \mathrm{~h}$ in $\mathrm{He}$ flow $\left(20 \mathrm{~mL} \mathrm{~min}^{-1}\right)$. All spectra were obtained by collecting 128 scans with $4 \mathrm{~cm}^{-1}$ resolution, against a $\mathrm{KBr}$ background (also measured at $120{ }^{\circ} \mathrm{C}$ in flowing $\mathrm{He}$ ).

\subsection{Photo-activity Measurements}

To evaluate catalyst performance in the selective oxidation of cyclohexane, reactions were carried out in a Top Illumination Reactor [4]. The catalysts were dried for $2 \mathrm{~h}$ at $120^{\circ} \mathrm{C}$ to remove adsorbed water and impurities. In a typical experiment $100 \mathrm{~mL}$ of cyclohexane containing $1 \mathrm{~g} \mathrm{~L}^{-1}$ of catalyst was used (slurry system). The suspension was illuminated from the top of the reactor through a Pyrex window that cuts off the highly energetic UV radiation [4]. A high pressure mercury lamp of $50 \mathrm{~W}$ was used (HBO50W from ZEISS). The light intensity of the lamp used in the wavelength absorption range of $\mathrm{TiO}_{2}(275-388 \mathrm{~nm})$ is $5.5 \mathrm{~W} \mathrm{~m}^{-2}$ entering the suspension. Air, dried over Molsieve 3 A (Acros Organics) and pre-saturated with cyclohexane, was bubbled through the $\mathrm{TiO}_{2}$ suspension at a rate of $30 \mathrm{~mL} \mathrm{~min}^{-1}$. During the reaction, liquid was withdrawn and analyzed by GC. Organic compounds were quantatively analyzed twice using a gas chromatograph with a flame ionization detector (Chrompack, CPwax52CB). Hexadecane was used as an internal standard.

\section{Results}

\subsection{Catalyst Characterization}

Figure 1 shows the $\mathrm{NH}_{3}-\mathrm{TPD}$ profiles obtained for each $\mathrm{TiO}_{2}$ sample. The profile of the Hombikat catalyst is in good agreement with the profile obtained in a previous study in our laboratory [4]. By integration of the TPD

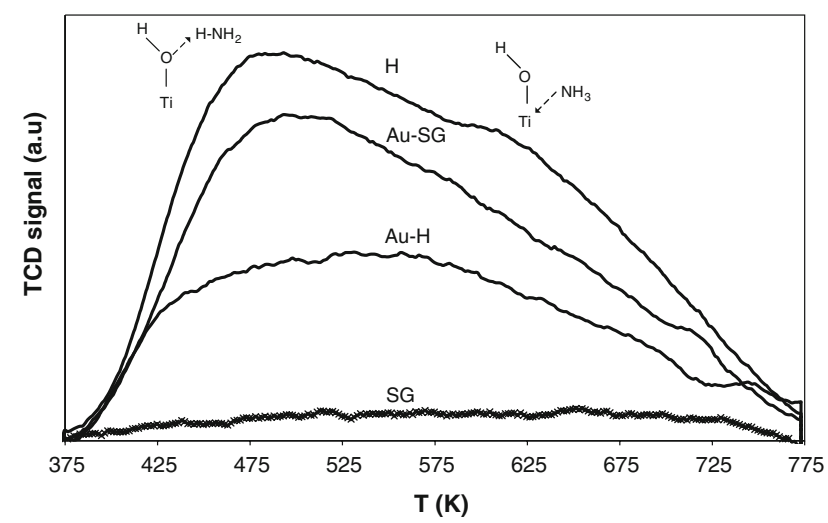

Fig. $1 \mathrm{NH}_{3}-\mathrm{TPD}$ profiles for the four catalysts studied with corresponding illustration of the ammonia coordination: weakly adsorbed ammonia at low temperatures, and strongly adsorbed at high temperatures curves over the whole temperature range (375-775K), the total amount of surface OH-groups was determined as indicated in Table 1. The Table also contains the corresponding $\mathrm{pH}$ values used in the last step of the preparation procedure, and the surface area as determined by the $\mathrm{N}_{2}$-BET method. Since Hombikat $(H)$ is a commercial catalyst, the $\mathrm{pH}$ of preparation is not known. The $\mathrm{Au}-\mathrm{H}$ sample contains only half the amount of hydroxyl groups as compared to commercial Hombikat, while the surface area did not change significantly. Figure 1 shows that the decrease in amount of $\mathrm{OH}$-groups was due to a decrease of both strong and weak acidic sites, suggesting that $\mathrm{Au}$ deposition leads to a non-selective loss of surface OH-groups. For the SG catalyst, a high surface area was measured, combined with a relatively small amount of surface $\mathrm{OH}$-groups. The reason for this observation will be discussed later by comparing the DRIFT spectra of the various samples.

Regarding the $\mathrm{Au}-\mathrm{SG}$ catalyst, the $\mathrm{N}_{2}$-physisorption results indicate a surface area similar to $\mathrm{Au}-\mathrm{H}$, with a higher amount of surface OH-groups being present as deduced from $\mathrm{NH}_{3}-\mathrm{TPD}$ profiles. In the case of the $\mathrm{TiO}_{2}$ prepared by the sol-gel method, Au deposition apparently leads to an increase of the amount of surface $\mathrm{OH}$-groups, as shown in Table 1. Summarizing, using the preparation variables applied here, a diverse set of $\mathrm{TiO}_{2}$ catalysts was obtained, containing a wide range of $\mathrm{OH}$-group densities $\left(\mathrm{mmol} \mathrm{g}^{-1}\right)$ and surface areas.

To further analyze the surface composition of the catalysts, we show in Fig. 2a the DRIFT spectra of $\mathrm{SG} \mathrm{TiO}_{2}$ before and after Au deposition. In the spectrum of SG, absorptions at 2,962,2,934 and $2,872 \mathrm{~cm}^{-1}$ are present, which correlate well with $\mathrm{C}-\mathrm{H}$ stretching vibrations of Titanium (IV) isopropoxide. Absorptions at 1,465 and $1,372 \mathrm{~cm}^{-1}$ are the corresponding $\mathrm{C}-\mathrm{H}$ bending modes. Clearly the spectrum reveals that not all the Titanium (IV) isopropoxide is hydrolyzed in the preparation procedure. For the Au-SG material the isopropoxide bands are no longer present. Upon Au deposition, the SG material was exposed to a $\mathrm{pH}$ of 7.5 in a $\mathrm{Na}_{2} \mathrm{CO}_{3}$ solution at $70{ }^{\circ} \mathrm{C}$, which is favorable for the hydrolysis of isopropoxide. By comparing the intensity of the spectra in the range of

Table 1 Synthesis $\mathrm{pH}$ of the three catalysts prepared, the resulting amount of acidic $\mathrm{OH}$-groups determined by $\mathrm{NH}_{3}-\mathrm{TPD}$, and the $\mathrm{N}_{2}-$ BET surface area of the catalysts studied

\begin{tabular}{llll}
\hline Catalyst & $\mathrm{pH}$ & $\mathrm{OH}\left(\mathrm{mmol} \mathrm{g}^{-1}\right)$ & SBET $\left(\mathrm{m}^{2} \mathrm{~g}^{-1}\right)$ \\
\hline $\mathrm{H}$ & - & 0.92 & 337 \\
$\mathrm{SG}$ & 3 & 0.11 & 400 \\
$\mathrm{Au}-\mathrm{H}$ & 6 & 0.50 & 329 \\
$\mathrm{Au}-\mathrm{SG}$ & 7.5 & 0.70 & 327 \\
\hline
\end{tabular}


3,300-3,800 $\mathrm{cm}^{-1}$, where OH-groups are expected [28], clearly the intensity after Au deposition on SG is higher, confirming the hydrolysis of isopropoxide groups, also in agreement with the $\mathrm{NH}_{3}-\mathrm{TPD}$ data (Table 1). Completing hydrolysis of isopropoxide also makes SG more hydophylic, as is evident from the intensity differences in the broad stretching modes of adsorbed water (remaining at $120{ }^{\circ} \mathrm{C}$ ), between 3,600 and $2,500 \mathrm{~cm}^{-1}$, and the corresponding bending modes centered at $1,630 \mathrm{~cm}^{-1}$.

For the $\mathrm{H}$ and $\mathrm{Au}-\mathrm{H}$ materials, the DRIFT spectra are shown in Fig. 2b. The OH- and water associated bands are less intense after $\mathrm{Au}$ deposition, in agreement with data presented in Table 1. The lower amount of water and $\mathrm{Ti}-\mathrm{OH}-$ groups found after Au deposition, is the result of the $\mathrm{pH}$ of the applied solution, which was at 6 : a condition known to lower the amount of acidic OH sites [29].

TEM pictures of the samples $\mathrm{Au}-\mathrm{SG}$ and $\mathrm{Au}-\mathrm{H}$ are shown in Fig. 3. The dark spots in the micrographs were confirmed to be gold by means of EDX analysis. Figure 3a shows some Au particles of large dimensions (20-60 nm), and a large fraction of about $70 \%$ of particles in the size range of 4-6 nm. For the Au-SG sample, Fig. 3b, big Au particles as in the case of the $\mathrm{Au}-\mathrm{H}$ were not observed, and
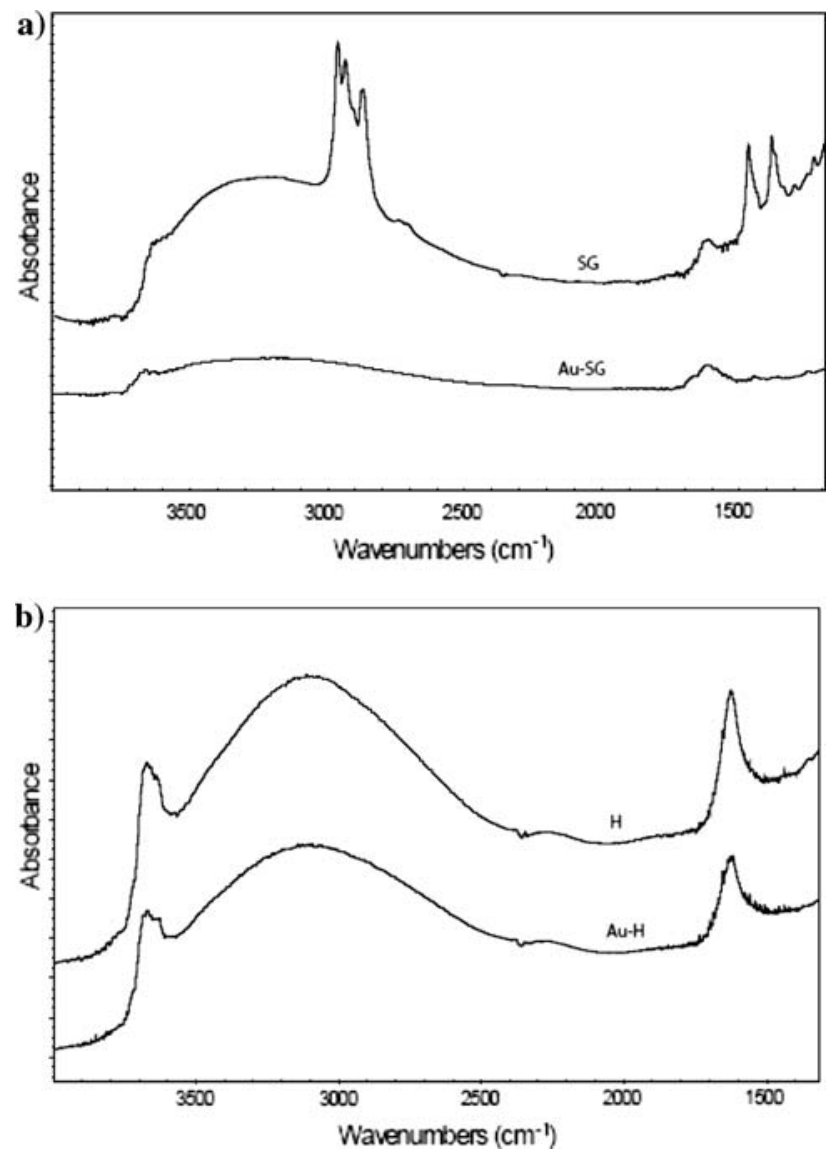

Fig. 2 IR spectra of the samples studied: a SG and Au-SG, b $\mathrm{H}$ and $\mathrm{Au}-\mathrm{H}$ around $90 \%$ of the particle sizes were in the range of 5$10 \mathrm{~nm}$.

The metal loading of the catalysts was determined by XRF. Although a loading of $1 \mathrm{wt} \%$ was aimed for, for the $\mathrm{Au}-\mathrm{SG}$ sample the obtained metal loading was $0.5 \mathrm{wt} \%$ and for $\mathrm{Au}-\mathrm{H}, 2.6 \mathrm{wt} \%$. Apparently the different surface composition of Hombikat relative to $\mathrm{P} 25$, for which the synthesis procedure was optimized [25], resulted in an excess of $\mathrm{Au}$ to be deposited. The relatively small $\mathrm{Au}$ loading of $\mathrm{Au}-\mathrm{SG}$ is most likely a consequence of the large degree of propoxylation of the SG-Anatase, limiting the initially present number of $\mathrm{OH}$-anchoring sites for the $\mathrm{Au}$ precursor species.

Absorbance spectra for the two Au catalysts are shown in Fig. 4. The absorbance fraction, $F_{\mathrm{A}}$, is the relative amount of photons actually attenuated by the catalyst layer. The absorption edge of $\mathrm{Au}-\mathrm{H}$ shows a slight blue shift from 365 to $360 \mathrm{~nm}$. This is related to the crystalline particle size, which is lower in Hombikat, as compared to $\mathrm{TiO}_{2}$ prepared by the sol-gel method. This was confirmed by XRD data, from which by application of the Scherrer equation, crystal sizes of $\sim 8 \mathrm{~nm}$ for $\mathrm{Au}-\mathrm{SG}$ and $\sim 6 \mathrm{~nm}$ for $\mathrm{Au}-\mathrm{H}$ were determined. Around $550 \mathrm{~nm}$ an absorption band can be observed which is due to the plasmon absorption of metallic Gold. The absorption in this area showed to be more accentuated in the $\mathrm{Au}-\mathrm{H}$ catalyst, as compared to the Au-SG catalyst, in particular considering the higher loading of the $\mathrm{Au}-\mathrm{H}$ catalyst. This again indicates a difference in particle size, and possibly also in the reduction degree of the $\mathrm{Au}$ present in the catalytic materials, which requires further analyses.

\subsection{Photocatalytic Oxidation of Cyclohexane}

Previous work in our group [4] showed that the main products of the cyclohexane selective photocatalytic oxidation are cyclohexanone and cyclohexanol, with a ketone to alcohol selectivity higher than $98 \%$. Cyclohexane conversion is very low, $<2 \%$ and $\mathrm{CO}_{2}$ contributions, due to complete oxidation, are not significant (cyclohexanone and cyclohexanol are reported to be produced with selectivities $>95 \%$ relative to $\mathrm{CO}_{2}$ ) [4]. While radical chemistry in solution can provide for other products, in view of the applied wavelengths $(>275 \mathrm{~nm})$ this is not expected to occur, as confirmed by our GC analyses.

Cyclohexanone formation upon photo-oxidation of cyclohexane is shown for the 4 applied catalysts in Fig. 5. The shape of the profiles is the result of catalyst deactivation, induced by carbonate and carboxylate formation on the catalyst surface [30]. The amount of cyclohexanone formed over the different catalysts follows the order $\mathrm{H}>\mathrm{Au}-\mathrm{SG}>\mathrm{Au}-\mathrm{H}>\mathrm{SG}$. After the Au deposition procedure, the activity of the SG catalyst is apparently largely 
Fig. 3 TEM pictures of the $\mathrm{Au}$ catalysts used in this study.

a $\mathrm{Au}-\mathrm{H}$ b $\mathrm{Au}-\mathrm{SG}$
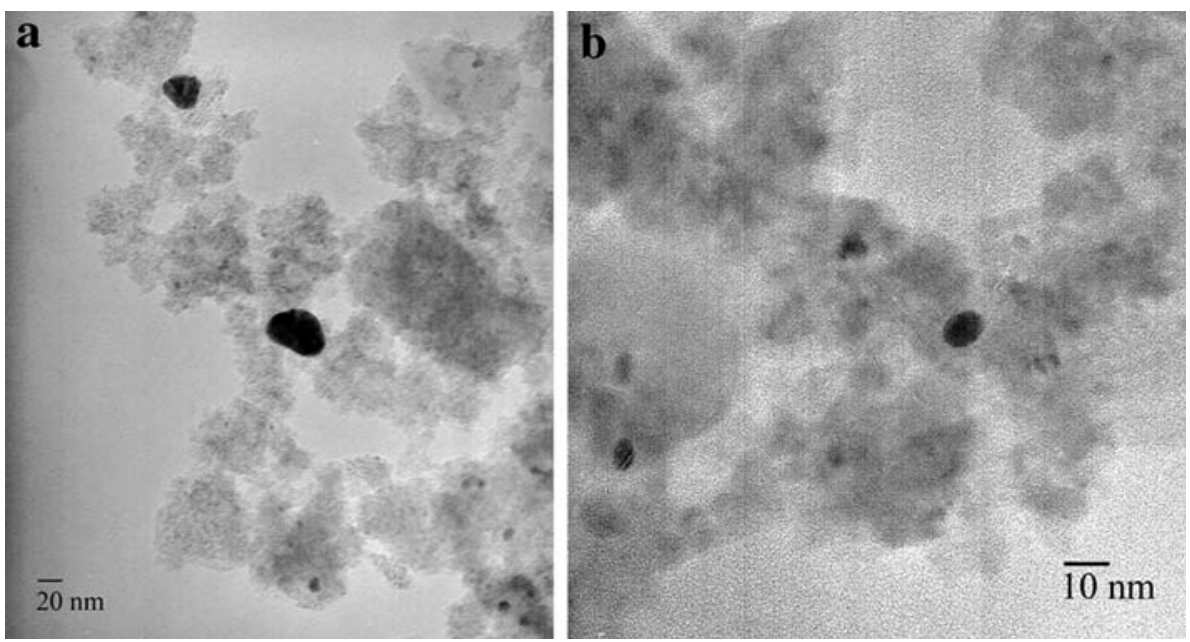

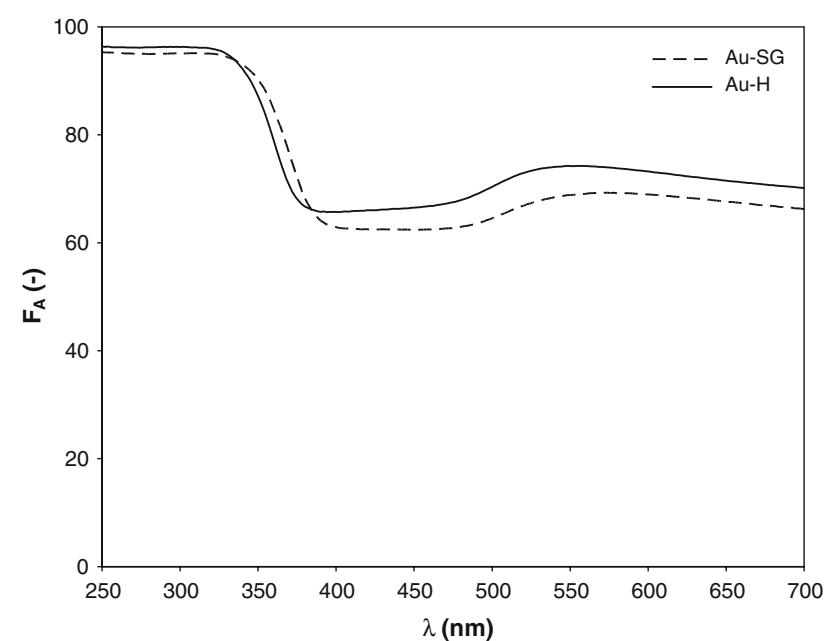

Fig. 4 UV/Vis spectra of the Au samples studied, as measured with an integrating sphere under ambient conditions

enhanced, whereas an opposite effect is observed for the $H$ catalyst.

In addition to cyclohexanone, the inset of Fig. 5a shows the amount of cyclohexanol produced for the materials under study. Albeit small, a different trend in catalyst behaviour for cyclohexanol production as compared to cyclohexanone was found, the production order being $\mathrm{Au}-\mathrm{H}>\mathrm{Au}-\mathrm{SG}>\mathrm{H}>\mathrm{SG}$. Cyclohexanol formation was below the GC detection limit for the SG material. Figure $5 \mathrm{~b}$ shows a comparison in cyclohexanone production of the $\mathrm{H}$ and $\mathrm{AuH}$ with the reference catalyst $\mathrm{HT} \mathrm{HCl}$, prepared in the exact same way as $\mathrm{Au}-\mathrm{H}$, but substituting $\mathrm{HAuCl}_{4}$ for $\mathrm{HCl}$. Please note that the time scales of (Fig. 5a, b) are different. Figure $5 \mathrm{~b}$ clearly shows that the preparation conditions largely affect the performance of $H$, irrespective of the presence of $\mathrm{Au}$ : the performance of $\mathrm{Au}-\mathrm{H}$ and $\mathrm{HT} \mathrm{HCl}$ is comparable. The inset of Fig. $5 \mathrm{~b}$ shows the one order of magnitude smaller cyclohexanol
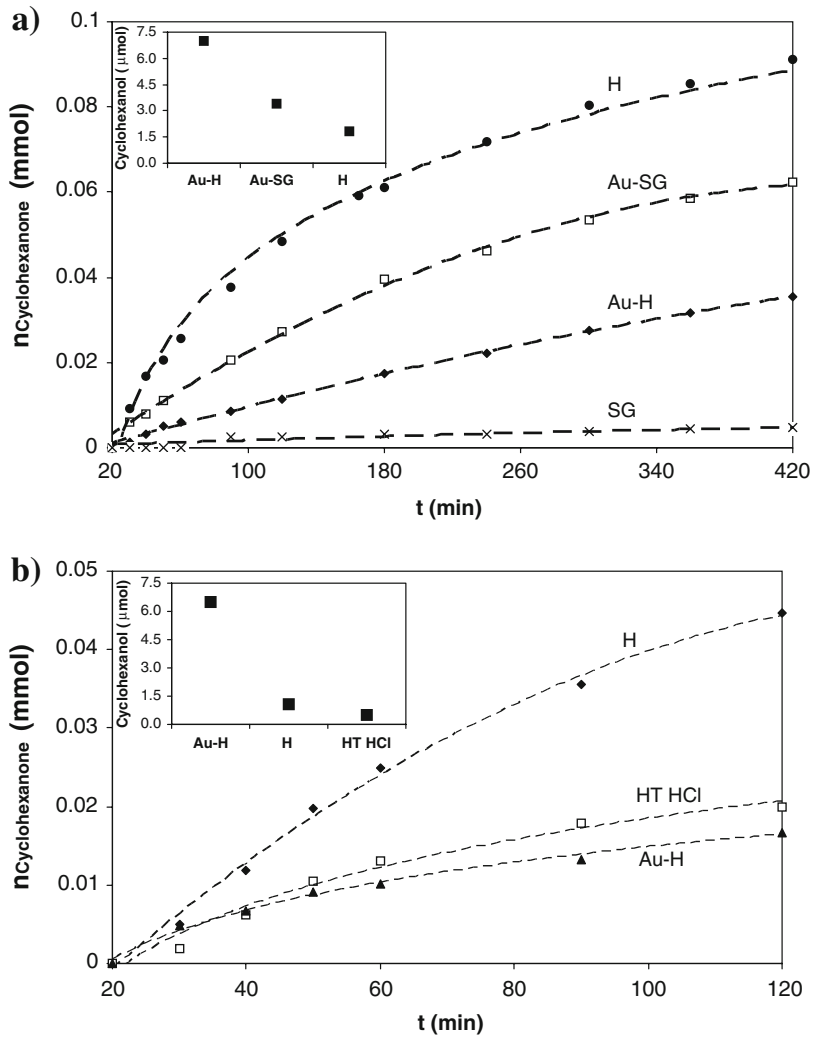

Fig. 5 a Cyclohexanone production profiles for $\mathrm{H}, \mathrm{Au}-\mathrm{H}, \mathrm{Au}-\mathrm{SG}$ and SG. The cyclohexanone value reaches a plateau after prolonged time of reaction, as a result of loss of activity of the catalyst. The inset shows the final cyclohexanol amounts obtained (at $t=420 \mathrm{~min}$ ). b Cylohexanone profiles for $\mathrm{H}, \mathrm{HT} \mathrm{HCl}$, and $\mathrm{Au}-\mathrm{H}$. The inset shows the final cyclohexanol amounts obtained (at $t=120 \mathrm{~min}$ )

production after $120 \mathrm{~min}$ of reaction: in agreement with Fig. 5a, Au has a positive affect on cyclohexanol production.

Figure 6 shows a plot of the estimated initial cycohexanone production rate using the amount produced at $t=40$, Fig. 5 as a function of the amount of OH-groups 


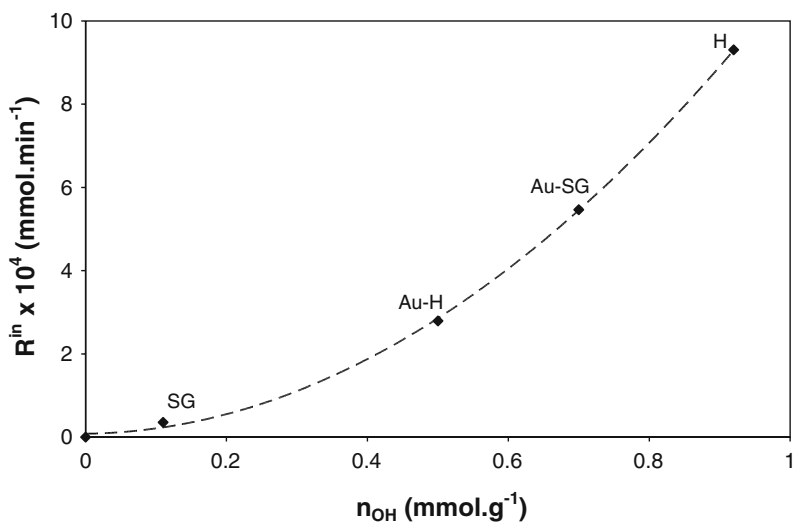

Fig. 6 Dependency of the initial total product formation rate on the initial amount of surface hydroxyl groups present on the catalyst surface

present on the $\mathrm{TiO}_{2}$ surface, as determined by the TPD experiment. An exponential correlation is obtained.

\section{Discussion}

\subsection{Effect of the Preparation Procedure on Catalyst Constitution}

Various research groups have reported a positive effect on photocatalytic performance of noble metal $(\mathrm{Pt}, \mathrm{Pd}, \mathrm{Au})$ deposition on the surface of $\mathrm{TiO}_{2}$ catalysts. Generally the enhancement in activity is attributed to an increased rate of charge separation and/or decreasing charge carrier recombination velocity $[19,21,23]$. The effect of the deposition of noble metals on the surface chemical properties of the catalyst (semiconductor oxide) is typically not taken into consideration. In the present study, it is apparent that the $\mathrm{Au}$ deposition procedure can dramatically affect the amount of surface OH-groups as is shown in Table 1 and evident from the DRIFT spectra in Fig. 2. The amount of $\mathrm{Au}$ is not enough to account for the large differences in the number of hydroxyl groups on the $\mathrm{TiO}_{2}$ surfaces. Alternatively, during the $\mathrm{Au}$ deposition procedure the $\mathrm{TiO}_{2}$ surface is exposed to conditions which induce the significant surface changes. Two surface chemical processes have been identified in the present study: (a) the hydrolysis of remaining Ti-isopropoxide groups, explaining the significant increase in the amount surface $\mathrm{OH}$-groups for the SG catalyst upon $\mathrm{Au}$ deposition and (b) solution induced removal of acid sites in the case of the $\mathrm{H}$ catalyst. In the latter case, the control experiments, shown in Fig. 5b, clearly indicate that the acid treatment of the catalyst upon $\mathrm{Au}$ deposition is the cause of the reduced activity of $\mathrm{Au}-\mathrm{H}$ compared to $\mathrm{H}$. The nature of the $\mathrm{OH}$-groups (Acid sites) on the catalyst surface will be discussed on the basis of the $\mathrm{NH}_{3}$-TPD spectra (Fig. 1) in the following.
It is believed that desorbed ammonia originates from ammonium ions $\left(\mathrm{NH}_{4}{ }^{+}\right)$and $\mathrm{NH}_{3}$ species molecularly coordinated to Lewis acid sites $[4,31]$. If the $\mathrm{NH}_{3}-\mathrm{TPD}$ profiles shown in Fig. 1 are deconvoluted they consist of two overlapping peaks which correspond to two types of adsorption strengths. The low-temperature peak (363543K) characterizes desorption states of ammonium ions and weakly coordinated ammonia (Fig. 1). The high temperature peak $(598-793 \mathrm{~K})$ is related to strongly coordinated ammonia at Lewis acid sites. All sites appear affected by the Au deposition procedure, leading to a nonselective change in the amount of acid sites [31].

In the following we will discuss why the hydroxyl groups are so important in determining the catalyst performance in photo-oxidation of cyclohexane, as is evident from the trend shown in Fig. 6.

\subsection{The Role of OH-groups in Photocatalytic Reactions in Organic Media}

Surface $\mathrm{OH}$-groups $\left(\mathrm{OH}_{\text {ads }}^{-}\right)$have been reported in the literature as being of great importance for the studied reaction [32] and in the degradation of pollutants [33, 34]. In Fig. 7, the initial steps of the selective photo-oxidation of cyclohexane are depicted, including cyclohexyl radical formation. In the beginning of the photo-process an electron-hole $\left(\mathrm{e}^{-}, \mathrm{h}^{+}\right)$pair is formed by light excitation of the semiconductor, $\mathrm{TiO}_{2}$. Once the electron and hole reach the surface of the catalyst, the hole is trapped by either a surface hydroxyl group $\left(\mathrm{OH}_{\text {ads }}^{-}\right)$or adsorbed water $\left(\mathrm{H}_{2} \mathrm{O}_{\text {ads }}\right)$, to form surface hydroxyl radicals. These surface hydroxyl radicals react with surface adsorbed cyclohexane, yielding a cyclohexyl radical. The electron interacts with the Ti(IV) center, that is reduced and further reacts with molecular oxygen to superoxide anions, $\mathrm{O}_{2}{ }^{-}$. The cyclohexyl radical combines with the superoxide anion, forming oxygenated products (i.e., cyclohexanone) [30]. Reactions involving free $\mathrm{OH}$ radicals are not considered here, since desorption of $\mathrm{OH}$ radicals into the organic solution is unlikely [35].

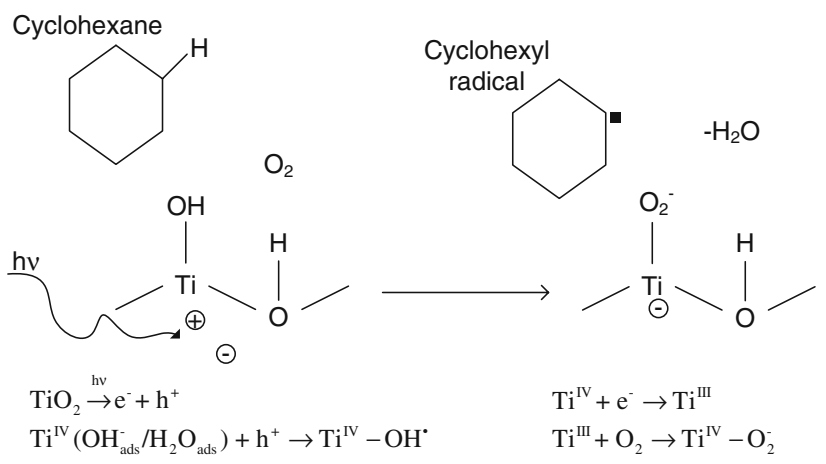

Fig. 7 Simplified scheme of $\mathrm{TiO}_{2}$ induced photocatalytic cyclohexane oxidation 
The message of Fig. 7 is that an important step in the formation of cyclohexanone is the reaction of cyclohexane with a $\mathrm{OH}$-radical originating from a surface $\mathrm{OH}$-group. Since the reaction is performed in a (dried) cyclohexane medium, the initial reaction rate is thus a strong function of the amount of hydroxyl groups initially present on the catalyst surface. The importance of surface $\mathrm{OH}$-groups is also illustrated by the rapid deactivation of the catalyst systems. Products are accumulating on the surface and interact with surface $\mathrm{OH}$-groups, thus limiting the reaction rate. It should be mentioned that since the samples are taken from the liquid, the amount of product measured is a lower limit of the amount actually formed [12].

\subsection{A Role of Gold?}

Clearly, for the initial reaction rate in cyclohexane oxidation the initial concentration of surface $\mathrm{OH}$-groups is much more important than the presence or absence of Au. However, a positive effect of gold has been observed in the literature for aqueous phase reactions. It is thus important to distinguish photo-catalysis performed in an aqueous medium (e.g., wastewater treatment) from that in organic medium (e.g., cyclohexane photo-oxidation) in evaluating the role of $\mathrm{Au}$. Considering a wastewater degradation type reaction, water and hydroxyl groups are present at high concentration on the catalyst surface, and less likely to be limiting the reaction. Photo-generated holes are constantly being trapped by the abundant presence of surface water and $\mathrm{OH}$-groups, and thus the amount of photo-generated holes might be limiting the reaction. Certainly, improving charge separation is needed in this case for a better catalyst performance. This justifies changing the opto-electronic properties of the catalyst, and most likely explains the observed effects of $\mathrm{Au}$ on photocatalytic performance in water phase reactions.

In the present study, Au deposition enhances the amount of cyclohexanol formed, the amount being still significantly smaller compared to cyclohexanone (see inset in Fig 5a, b). This phenomenon requires further investigation, but might indicate that $\mathrm{Au}$ affects the decomposition chemistry of cyclohexyl hydroperoxide, which is often considered the intermediate in the photon induced formation of cyclohexanone [12]. The electron trapping effect of $\mathrm{Au}$ might also induce a higher amount of superoxide anion $\left(\mathrm{O}_{2}{ }^{-}\right.$, Fig. 7), leading to the observed selectivity changes. The opto-electronic changes that $\mathrm{Au}$ induces in a semiconductor like $\mathrm{TiO}_{2}$ (anatase and/or rutile phase), are currently further analyzed in our laboratory, to validate the claims made in the literature and to support the above hypothesis for enhanced cyclohexanol formation.

In order to improve catalytic performance in selective oxidation reactions such as the one studied, increasing the amount of surface $\mathrm{OH}$-groups on the semiconductor surface should be established. This could be achieved, e.g., by pre-treatment of the catalysts by (mild) steaming.

\section{Conclusions}

Gold deposition on Hombikat negatively affects the activity of this Anatase catalyst in selective photo-oxidation of cyclohexane, explained by a significant modification of the surface $\mathrm{OH}$-population of the catalyst induced by the Au preparation procedure as determined by ammonia TPD and DRIFT spectroscopy. When a photoreaction is performed in an organic medium, the initial amount of surface hydroxyl groups is apparently largely affecting the initial rate. This was confirmed by the experiments performed with a surface propoxylated SolGel catalyst, before and after $\mathrm{Au}$ deposition. Surface modifications of the $\mathrm{TiO}_{2}$ as a result of the preparation procedure, and the deposition recipe of noble metals should thus be taken into account in evaluating and explaining photocatalytic performance of $\mathrm{TiO}_{2}$, in particular in nonaqueous phase reactions.

Acknowledgments We would like to acknowledge the X-ray facilities of the 3ME Department, Faculty of Applied Sciences, of the Delft University of Technology for the X-Ray analyses. Dr. ing. V. C. L. Butselaar of DCT/NCHREM, Delft University of Technology, is acknowledged for performing the electron microscopy investigations, and Sander Brouwer for performing the $\mathrm{NH}_{3}-\mathrm{TPD}$ and $\mathrm{N}_{2}$ physisorption measurements. STW (VIDI Project DPC.7065), is gratefully acknowledged for financial support.

Open Access This article is distributed under the terms of the Creative Commons Attribution Noncommercial License which permits any noncommercial use, distribution, and reproduction in any medium, provided the original author(s) and source are credited.

\section{References}

1. Almquist CB, Biswas P (2001) Appl Catal A-Gen 214(2):259

2. Boarini P, Carassiti V, Maldotti A, Amadelli R (1998) Langmuir 14(8):2080

3. Brusa MA, Di Iorio Y, Churio MS, Grela MA (2007) J Mol Catal A-Chem 268(1-2):29

4. Du P, Moulijn JA, Mul G (2006) J Catal 238(2):342

5. Giannotti C, Legreneur S, Watts O (1983) Tetrahedron Lett 24(46):5071

6. Herrmann JM, Mu W, Pichat P (1991) Stud Surface Sci Catal 59:405

7. Li XY, Chen GH, Po-Lock Y, Kutal C (2003) J Chem Technol Biotechnol 78(12): 1246

8. Li XY, Quan X, Kutal C (2004) Scr Mater 50(4):499

9. Lu GX, Gao HX, Suo JH, Li SB (1994) J Chem Soc-Chem Commun 21:2423

10. $\mathrm{Mu} \mathrm{W}$, Herrmann JM, Pichat P (1989) Catal Lett 3(1):73

11. Su BT, He YF, Li XY, Lin EH, Li QL (1997) Indian J Chem Sect A-Inorg Bio-Inorg Phys Theor \& Anal Chem 36(9):785 
12. Du P, Cameiro JT, Moulijn JA, Mul G (2008) Appl Catal A-Gen 334(1-2):119

13. Van Gerven T, Mul G, Moulijn J, Stankiewicz A (2008) Chem Eng Process 46(9):781

14. Augugliaro V, Litter M, Palmisano L, Soria J (2006) J Photochem Photobiol C-Photochem Rev 7(4):127

15. Bahnemann D (2004) Sol Energy 77(5):445

16. Dillert R, Cassano AE, Goslich R, Bahnemann D (1999) Catal Today 54(2-3):267

17. Arana J, Dona-Rodriguez JM, Cabo CGI, Gonzalez-Diaz O, Herrera-Melian JA, Perez-Pena J (2004) Appl Catal B-Environ 53(4):221

18. Peral J, Domenech X, Ollis DF (1997) J Chem Technol Biotechnol 70(2):117

19. Li HX, Bian ZF, Zhu J, Huo YN, Li H, Lu YF (2007) J Am Chem Soc 129(15):4538

20. Orlov A, Jefferson DA, Macleod N, Lambert RM (2004) Catal Lett 92(1-2):41

21. Sonawane RS, Dongare MK (2006) J Mol Catal A-Chem 243(1):68

22. Chan SC, Barteau MA (2005) Langmuir 21(12):5588
23. Sakthivel S, Shankar MV, Palanichamy M, Arabindoo B, Bahnemann DW, Murugesan V (2004) Water Res 38(13):3001

24. Sreethawong T, Yoshikawa S (2005) Catal Commun 6(10):661

25. Yu WY, Lee WS, Yang CP, Wan BZ (2007) J Chin Inst Chem Eng 38(2):151

26. Mohapatra P, Moma J, Parida KM, Jordaan WA, Scurrell MS (2007) Chem Commun 10:1044

27. Haruta M (1997) Catal Today 36(1):153

28. Panayotov DA, Yates JT (2005) Chem Phys Lett 410(1-3):11

29. Kozlov D, Bavykin D, Savinov E (2003) Catal Lett 86(4):169

30. Almeida AR, Moulijn JA, Mul G (2008) J Phys Chem C 112(5): 1552

31. Popova NM, Sokolova LA, Marchenko EA, Bobrova LN (1998) React Kinet Catal Lett 65(2):371

32. Gonzalez MA, Howell SG, Sikdar SK (1999) J Catal 183(1):159

33. Turchi CS, Ollis DF (1990) J Catal 122(1):178

34. Okamoto K, Yamamoto Y, Tanaka H, Tanaka M, Itaya A (1985) Bull Chem Soc Jpn 58(7):2015

35. Lawless D, Serpone N, Meisel D (1991) J Phys Chem 95(13):5166 